\title{
Quantitative real-time PCR for the clinical detection of Helicobacter pylori
}

\author{
Marcelo Lima Ribeiro, Christina Cunha Ecclissato, Ricardo Gabriel Mattos, Sergio Mendonca \\ and José Pedrazzoli Jr. \\ Unidade Integrada Farmacologia e Gastroenterologia, Universidade São Francisco, \\ Bragança Paulista, SP, Brasil.
}

\begin{abstract}
Accurate diagnosis of Helicobacter pylori infection is very important in both clinical practice and research. We evaluated the sensitivity of real-time PCR (RT-PCR) for the detection and quantification of Helicobacter pylori using DNA from 91 human gastric biopsy samples divided into three groups: 46 biopsies from untreated patients who according to the references methods were considered $H$. pylori-negative (group A); 35 biopsies from patients previously treated against $H$. pylori and considered to be cured by "gold standard" tests (group B); and 10 biopsies from patients $H$. pylori-positive by all available methods (group C). The sensitivity of the RT-PCR assay was higher than that of standard methods. Of the 81 patients considered to be uninfected according to the references methods, 16 were $\mathrm{H}$. pylori-positive by PCR, 10 of which were patients who had received H. pylori eradication therapy and 6 were untreated patients. Based on these findings we recommend that RT-PCR should be use in addition to standard methods in clinical studies to monitor the results of $H$. pylori eradication therapy.
\end{abstract}

Key words: diagnostic methods, Helicobacter pylori, real-time PCR.

Received: July 5, 2006; Accepted: November 6, 2006.

One of the most common chronic infections in humans is the bacteria Helicobacter pylori (Graham, 2000), which is considered to be the major causative agent of gastritis and a key etiological factor in peptic ulcer disease, gastric cancer and MALT (Mucosa-Associated Lymphoid Tissue) [Undefined acronym.] lymphoma (Blaser, 1990; Marshall, 1994). Infection with H. pylori can be effectively treated by the combination of a proton pump inhibitor with multiple antibiotics but although the bacteria can be eradicated in up to $90 \%$ of patients side effects, poor compliance and resistance to the antibiotics used are common causes of treatment failure (Megraud and Doermann, 1998; de Boer and Borody, 2000).

Accurate diagnosis of $H$. pylori infection is very important in both clinical practice and for research purposes and several invasive and noninvasive methods for $H$. pylori detection are currently available. In all invasive procedures gastric biopsies are required coupled with tests such as the rapid urease test (RUT), bacteriological culture, tissue histology and PCR-based diagnostic, while the noninvasive tests include direct fecal antigen detection, serology, urea breath testing and PCR of saliva, dental plaques or stool

Send correspondence to Marcelo Lima Ribeiro. Clinical Pharmacology and Gastroenterology Unit, São Francisco University Medical School, Av. São Francisco de Assis 218, 12916-900 Bragança Paulista, SP, Brazil. E-mail: marcelo.ribeiro@saofrancisco.edu.br. samples (Versalovic, 2003). Although the sensitivity and specificity of diagnostic tests for $\mathrm{H}$. pylori detection vary from satisfactory to very good, several studies have shown that the sensitivity of methods such as bacterial culture, RUT, histology and stool antigen tests could be unreliable when few bacteria are present (Ho et al., 1991). Additionally, serology cannot detect the clearance of $H$. pylori and urease assays can lead to non-specific results due to the presence of other urease-positive bacteria and false negative results have also been reported in individuals taking proton pump inhibitors (Mobley et al., 1991; Graham et al., 2003). Methods based on molecular biology are considered highly specific and sensitive tests, and many PCR-based assays have been developed to detect $H$. pylori DNA in gastric biopsies, saliva and stool samples (Li et al., 1996; Pacheco et al., 2001). However, this technique is able to detect specific fragments but not viable bacteria and its sensitivity also depends on the amount of bacterial DNA (Pacheco et al., 2001).

Recently, real-time PCR (RT-PCR) quantitative assays have been developed to quantify $H$. pylori in gastric and stool samples (He et al., 2002; Kobayashi et al., 2002; Lascols et al., 2003; Mikula et al., 2003; SchabereiterGurtner et al., 2004). These methods allow rapid and accurate quantification of $H$. pylori and have increased in importance because they can facilitate the monitoring of 
therapy and even measure the effectiveness of vaccines against $H$. pylori (He et al., 2002).

The sensitivity and specificity of the currently available tests for $\mathrm{H}$. pylori detection may be affected by several factors and more reliable methods are desirable. We described the applicability and sensitivity of RT-PCR for $H$. pylori detection and quantification in 81 biopsies from patients considered to be non-infected and 10 biopsies from H. pylori-positive patients.

We collected 91 human gastric biopsy samples from patients with dyspeptic symptoms who presented themselves at the Clinical Pharmacology and Gastroenterology Unit of São Francisco Medical School (Bragança Paulista, SP, Brazil). This study was approved by the Ethics Committee of São Francisco University, and was done in accordance with the Declaration of Helsinki. Each patient signed a written informed consent prior to entering the study.

All data regarding $H$. pylori detection (RUT, histology and culture) were available and have been published previously (Mendonca et al., 2000; Ecclisatto et al., 2002). We determined Helicobacter pylori infection using rapid urease test in one antral biopsy (Probac, São Paulo, Brazil), histological evaluation (hematoxylin and eosin and Giemsa staining) and culture using two samples (one for each method) from the antrum, corpus and fundus.

The 91 human gastric biopsy samples ( 81 uninfected, 10 infected) formed three groups: 46 biopsies from untreated patients who according to the references methods were $H$. pylori-negative (group A); 35 biopsies from patients previously treated against $H$. pylori and considered to be cured by "gold standard" tests (group B); and 10 biopsies from patients $H$. pylori-positive by all available methods (group C). The patients from group B were treated twice a day for 7 days with lansoprazole $30 \mathrm{mg}$ (Ogastro ${ }^{\circledR}$, Abbott, Brazil), amoxicillin $1000 \mathrm{mg}$ (Amoxil®, Smith Kline Beecham, Brazil) and clarithromycin $500 \mathrm{mg}$ (Klaricid®, Abbott, Brazil). The patients were re-evaluated at the end of therapy by a second endoscopic examination 30 days following successful completion of the therapy in order to assess H. pylori eradication and ulcer healing. Healing of peptic lesions was considered as the absence of ulcers in previously injured mucosa, or the presence of a definite scar. Antrum, corpus and fundus biopsies were taken to determine the presence of $H$. pylori as previously described. Eradication was defined by a negative culture, histology and urease test.

Frozen biopsy samples were thawed at room temperature transferred to a microcentrifuge tubes and centrifuged at $10.000 \mathrm{~g}$ for $5 \mathrm{~min}$. The supernatant was decanted and $300 \mu \mathrm{L}$ of extraction buffer (containing $20 \mathrm{mM}$ Tris-Hcl (pH 8.0) and $0.5 \%(\mathrm{v} / \mathrm{v})$ Tween 20$)$ was added and the pellet resuspended by vortexing, after which Proteinase K (Sigma Chemical CO., St. Louis, MO) was added to a final concentration of $0.5 \mathrm{mg} \mathrm{mL}^{-1}$. After overnight incubation at $37^{\circ} \mathrm{C}$ the DNA was extracted by a phenol-chloroform method and the absorbance at $260 / 280 \mathrm{~nm}$ determined for each sample.

The DNA samples obtained were subjected to a realtime PCR, performed in an iCycler IQ (Bio-Rad, Hercules, CA, USA), data acquisition and analysis were carried out using the Real-Time Detection System Software (Bio-Rad). The RT-PCR was targeted at the $26 \mathrm{KDa}$ Helicobacter species-specific antigen (SSA) gene (O'Toole et al., 1991) and a double-stranded DNA-specific dye SYBR Green I was used. The $50 \mu \mathrm{L}$ reaction mixture was composed of follows: $25 \mu \mathrm{L}$ of iQ SYBR ${ }^{\circledR}$ Green Supermix (Bio-Rad), $50 \mathrm{nM}$ of each primer (forward: 5'-TGGCG TGTCTATTGACAGCGAGC-3', reverse: 5'-CCTGCTG GGCATACTTCACCATG-3') previously described (Mikula et al., 2003), $1 \mu \mathrm{L}$ of extracted DNA (200 ng).The reaction was cycled with preliminary denaturation for $5 \mathrm{~min}$ at $95{ }^{\circ} \mathrm{C}$, followed by 45 cycles of denaturation at $95^{\circ} \mathrm{C}$ for $30 \mathrm{~s}$, annealing at $65{ }^{\circ} \mathrm{C}$ for $30 \mathrm{~s}$ and primer extension at $72{ }^{\circ} \mathrm{C}$ for $30 \mathrm{~s}$. This was followed by melting point analysis of the double-stranded amplicons consisting of 40 cycles of $1{ }^{\circ} \mathrm{C}$ decrement (45 s each) beginning at $95{ }^{\circ} \mathrm{C}$. Positive controls consisted of genomic DNA extracted from $H$. pylori reference strains 26695 and J99, kindly provided by dr. Johannes G. Kusters (Erasmus Medical Center, Rotterdam, The Netherlands) and negative controls were provided by DNA isolated from blood samples and gastric mucosa of uninfected mice (strain C57BL/6,CEMIB/ UNICAMP, Campinas, SP, Brazil).

A significant change in fluorescence accompanies the melting curve of the double-stranded PCR products and the rate of change (d) of fluorescence $(\mathrm{F})$ in the reaction with time ( $\mathrm{T}$ ) is given by the first derivative $\mathrm{dF} / \mathrm{dT}$, a plot of $-\mathrm{dF} / \mathrm{dT}$ against temperature displaying these changes as distinct peaks.

To evaluate the detection limit of this reaction, serially diluted samples of $H$. pylori DNA ranging from $10^{-1}$ to $10^{6} \mathrm{fg}$ were used as a template. The efficiency was determined by standard curves on the basis of 10 -fold serial dilutions of $H$. pylori DNA in a background of $200 \mathrm{ng}$ of human DNA. Each sample was tested in triplicate and the mean calculated to obtain the final threshold cycle $(\mathrm{Ct})$, i.e., the point at which sample fluorescence rises above the background level. A standard curve, constructed by plotting the $\log$ of the initial DNA concentration versus the $\mathrm{Ct}$ value was used to determine $H$. pylori DNA concentrations. Comparisons of $\mathrm{Ct}$ values and the number of bacterial cells between the three groups were performed with the $t$ test, a p value of $<0.05$ being considered statistically significant.

The sensitivity of the RT-PCR assay was determined by adding serial 10 -fold dilutions ranging from $10^{-1}$ to $10^{6}$ fg of $H$. pylori chromosome DNA to a background of human DNA. The lowest $H$. pylori DNA concentration detected was $10 \mathrm{fg}$, equivalent to 5 bacterial cells (Mikula et al., 2003; Schabereiter-Gurtner et al., 2004). In a range between 10 to $10^{6}$ fg correlation coefficients, obtained by lin- 
ear regression analysis from all independent experiments, were higher than $R^{2}=0.99$, indicating highly efficient and reproducible reactions. The specificity of the reaction was determined by melting curve analysis and in all dilutions a single product was observed.

The number of bacterial cells and amount of DNA present in each sample were quantified by interpolation of the corresponding $\mathrm{Ct}$ values in the standard curves. The RT-PCR results from SSA amplification showed that of the 81 patients considered to be uninfected according to the references methods 16 were $H$. pylori-positive by RT-PCR, of which $6(13 \%)$ were group A untreated patients considered to be $H$. pylori negative by the reference methods and 10 $(29 \%)$ were group B treated patients also considered to be H. pylori negative by standard methods. As expected, all group C patients were $H$. pylori positive by RT-PCR.

The number of bacterial cells per $200 \mathrm{ng}$ of total DNA were quantified by real-time PCR and varied from 49 to 160 among the group B patients (the lowest $H$. pylori infection rates) to between 150 and 1400 in the group A patients and from 1000 to 31000 in the H. pylori-positive group C patients with the highest infection rates (Figure 1). Additionally, statistical analysis showed that the $\mathrm{Ct}$ and the bacterial load were significantly different among the patients from groups A, B and C ( $<<0.02)$. The reproducibility of the RT-PCR assay was also evaluated among the $26 \mathrm{H}$. pylori-positive patients (i.e. the 16 detected by RT-PCR plus the 10 in group C) with analysis of variance showing that there was no significant difference within or between runs, thus indicating that the assays were reproducible (data not shown).

Recently, five studies have shown that RT-PCR can be used to detect and quantify $H$. pylori DNA directly from gastric biopsy samples (He et al., 2002; Kobayashi et al., 2002; Lascols et al., 2003; Mikula et al., 2003; Schabereiter-Gurtner et al., 2004). Additionally, RT-PCR has been validated for the quantitative analysis of the low level of bacterial infection in immunized and experimentally infected mice, suggesting that this methodology may also be

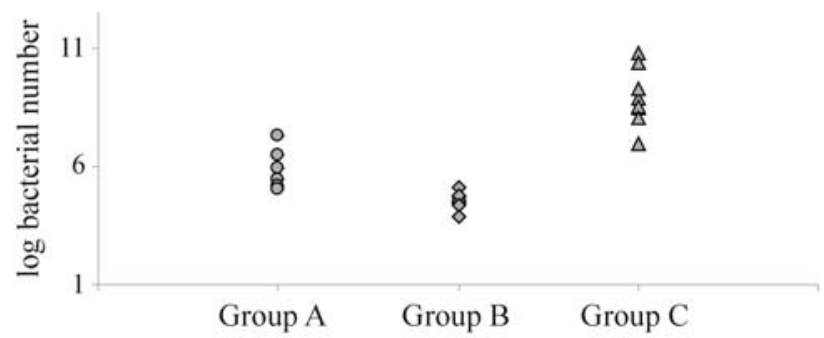

Figure 1 - Number of Helicobacter pylori per $200 \mathrm{ng}$ of total DNA for the different biopsy sample groups. Group A, consisting of 46 biopsies from untreated patients who according to the references methods were considered H. pylori-negative, showed an intermediary level of infection. Group $\mathrm{B}$, made up of 35 biopsies from patients previously treated against $H$. pylori and considered to be cured by "gold standard" tests, demonstrated a low level of infection. Group C, containing 10 biopsies from patients regarded as $H$. pylori-positive by means of all used methods, exhibited a high level of infection. useful for the evaluation of new anti-H. pylori drugs and vaccines (Mikula et al., 2003).

Our results show that the sensitivity of the RT-PCR assay was higher than that of the standard reference methods RUT, bacteriological analysis and histology, supporting the findings of other workers (He et al., 2002; Lascols et al., 2003; Schabereiter-Gurtner et al., 2004). Indeed, 16 of the 81 "uninfected" patients actually gave large numbers of H. pylori DNA copies when assessed by RT-PCR.

Standard methods are also useful for quantification, although each technique has its drawbacks. Bacteriological culture and histology allow only the semi-quantitative determination of infection, and both require experienced professionals for their execution and the interpretation of results (Christensen et al., 1992; Atherton et al., 1996; El-Zimaity et al., 1996; Leodolter et al., 2001). On the other hand, the RT-PCR assay can accurately detect and quantify five bacterial cells per $200 \mathrm{ng}$ of human DNA as previously described (Mikula et al., 2003; SchabereiterGurtner et al., 2004). Our results indicated that there was a significant difference in the bacterial density between the three groups analyzed. As expected, patients belonging to group $\mathrm{C}$ had the highest $H$. pylori population. The differences detected among the supposedly eradicated group (B) and untreated patients (A) may be attributed to the drugs used for eradication (He et al., 2002) and/or sampling errors that might generate differences in colonization density (Nedenskov-Sorensen et al., 1991). An additional possibility is that some group A patients took, but did not report, proton pump inhibitors, leading to false negative results in the currently used tests for H. pylori (Graham et al., 2003).

Although it has been shown that the detection sensitivity of "gold standard" methods for $H$. pylori is highly reduced when the density of $H$. pylori is low and their distribution is "patchy" (Leodolter et al., 2001; Vaira et al., 2002) our results indicated that biopsies from all the patients considered to be negative had an $H$. pylori density higher than 10000 cells, as previously reported by He et al. (2002). Growing evidence supports the concept that $H$. pylori exists in two viable forms, spiral or coccoid, and several studies have shown that the coccoid form cannot be cultured or be detected by RUT or histology but can be detected PCR (Bode et al., 1993; Chan et al., 1994; Hulten et al., 1996; Moayyedi and Dixon, 1998; He et al., 2002). Consequently, another possible explanation for our findings could be a high percentage of the coccoid form of $H$. pylori as a result of antibiotic treatment in the patients from group B. Additionally, He et al. (2002) have suggested the possibility that no viable $\mathrm{H}$. pylori were present in the biopsy sample but only dead bacteria or chromosomal DNA. However, we do not know how long the bacteria or the DNA can remain in the stomach.

Several studies have shown that the eradication of $H$. pylori plays an important role in the treatment of some gastrointestinal diseases (Tytgat, 1994) and the results of all 
currently used tests for bacterial detection can be affected by the treatment (Leodolter et al., 2001; Vaira et al., 2002). In conclusion, our findings show that the real-time PCR assay allows accurate and fast quantification of H. pylori DNA from gastric samples and should also be used to monitor treatment.

\section{Acknowledgments}

This work was supported by the Brazilian agency Fundacao de Amparo a Pesquisa do Estado de Sao Paulo grant number 01/10065-5.

\section{References}

Atherton JC, Tham KT, Peek RM, Cover TL and Blaser MJ (1996) Density of Helicobacter pylori infection in vivo as assessed by quantitative culture and histology. J Infect Dis 174:552-556.

Blaser MJ (1990) Helicobacter pylori and the pathogenesis of gastroduodenal inflammation. J Infect Dis 161:626-633.

Bode G, Mauch F and Malfertheiner P (1993) The coccoid forms of Helicobacter pylori. Criteria for their viability. Epidemiology Infection 111:483-490.

Chan WY, Hui PK, Leung KM, Chow J, Kwok F and Ng CS (1994) Coccoid forms of Helicobacter pylori in the human stomach. Am J Clin Pathol 102:503-507.

Christensen AH, Gjorup T, Hilden J, Fenger C, Henriksen B, Vyberg M, Ostergaard K, et al. (1992) Observer homogeneity in the histologic diagnosis of Helicobacter pylori. Latent class analysis, kappa coefficient, and repeat frequency. Scand J Gastroenterol 27:933-939.

de Boer WA and Borody TJ (2000) Treatment failures and secondary resistance to antibiotics. A growing concern in Helicobacter pylori therapy. Dig Liver Dis 32:673-675.

Ecclissato C, Marchioretto MA, Mendonca S, Godoy AP, Guersoni RA, Deguer M, Piovesan H, et al. (2002) Increased primary resistance to recommended antibiotics negatively affects Helicobacter pylori eradication. Helicobacter 7:53-59.

el-Zimaity HM, Graham DY, al-Assi MT, Malaty H, Karttunen TJ, Graham DP, Huberman RM, et al. (1996) Interobserver variation in the histopathological assessment of Helicobacter pylori gastritis. Hum Pathol 27:35-41.

Graham DY, Opekun AR, Hammoud F, Yamaoka Y, Reddy R, Osato MS and El-Zimaity HM (2003) Studies regarding the mechanism of false negative urea breath tests with proton pump inhibitors. Am J Gastroenterol 98:1005-1009.

Graham DY (2000) Helicobacter pylori infection is the primary cause of gastric cancer. J Gastroenterol Suppl 12:90-97.

He Q, Wang JP, Osato M and Lachman LB (2002) Real-time quantitative PCR for detection of Helicobacter pylori. J Clin Microbiol 40:3720372-8.

Ho SA, Hoyle JA, Lewis FA, Secker AD, Cross D, Mapstone NP, Dixon MF., et al. (1991) Direct polymerase chain reaction test for detection of Helicobacter pylori in humans and animals. J Clin Microbiol 29:2543-2549.

Hulten K, Han SW, Enroth H, Klein PD, Opekun AR, Gilman RH, Evans DG et al. (1996) Helicobacter pylori in the drinking water in Peru. Gastroenterology 110:1031-1035.

Kobayashi D, Eishi Y, Ohkusa T, Ishige I, Suzuki T, Minami J, Yamada T, Takizawa T and Koike M (2002) Gastric mucosal density of Helicobacter pylori estimated by real-time
PCR compared with results of urea breath test and histological grading. J Med Microbiol 51:305-311.

Lascols C, Lamarque D and Costa JM (2003) Fast and accurate quantitative detection of Helicobacter pylori and identification of clarithromycin resistance mutations in H. pylori isolates from gastric biopsy specimens by real-time PCR. J Clin Microbiol 41:4573-4577.

Leodolter A, Wolle K and Malfertheiner P (2001) Current standards in the diagnosis of Helicobacter pylori infection. Dig Dis 19:116-122.

Li C, Ha T, Ferguson DA Jr, Chi DS, Zhao R, Patel NR, Krishnaswamy G, et al. (1996) A newly developed PCR assay of $H$. pylori in gastric biopsy, saliva, and feces. Evidence of high prevalence of $H$. pylori in saliva supports oral transmission. Dig Dis Sci 41:2142-2149.

Marshall BJ (1994) Helicobacter pylori. American J Gastroenterol Suppl 8:S116-128.

Megraud F and Doermann HP (1998) Clinical relevance of resistant strains of Helicobacter pylori: A review of current data. Gut Suppl 1:61-65.

Mendonca S, Ecclissato C, Sartori MS, Godoy AP, Guerzoni RA, Degger M and Pedrazzoli J Jr (2000) Prevalence of Helicobacter pylori resistance to metronidazole, clarithromycin, amoxicillin, tetracycline, and furazolidone in Brazil. Helicobacter 5:79-83.

Mikula M, Dzwonek A, Jagusztyn-Krynicka K and Ostrowski J (2003) Quantitative detection for low levels of Helicobacter pylori infection in experimentally infected mice by real-time PCR. J Microbiol Methods 55:351-359.

Moayyedi P and Dixon MF (1998) Any role left for invasive tests? Histology in clinical practice. Gut Suppl 1:S51-55.

Mobley HL, Hu LT and Foxal PA (1991) Helicobacter pylori urease: Properties and role in pathogenesis. Scandinavian J Gastroenterol 187:39-46.

Nedenskov-Sorensen P, Aase S, Bjorneklett A, Fausa O and Bukholm G (1991) Sampling efficiency in the diagnosis of Helicobacter pylori infection and chronic active gastritis. J Clin Microbiol 672-675.

O'Toole PW, Logan SM, Kostrzynska M, Wadstrom T and Trust TJ (1991) Isolation and biochemical and molecular analyses of a species-specific protein antigen from the gastric pathogen Helicobacter pylori. J Bacteriol 173:505-513.

Pacheco N, Mago V, Gomez I, Gueneau P, Guelrud M, Reyes N, Pericchi LR, et al. (2001) Comparison of PCR and common clinical tests for the diagnosis of H. pylori in dyspeptic patients. Diagn Microbiol Infect Dis 39:207-210.

Schabereiter-Gurtner C, Hirschl AM, Dragosics B, Hufnagl P, Puz S, Kovach Z, Rotter M, et al. (2004) Novel real-time PCR assay for detection of Helicobacter pylori infection and simultaneous clarithromycin susceptibility testing of stool and biopsy specimens. J Clin Microbiol 42:4512-4518.

Tytgat GN (1994) Review article: Treatments that impact favourably upon the eradication of Helicobacter pylori and ulcer recurrence. Aliment Pharmacol Ther 8:359-368.

Vaira D, Vakil N, Menegatti M, van't Hoff B, Ricci C, Gatta L, Gasbarrini G, et al. (2002) The stool antigen test for detection of Helicobacter pylori after eradication therapy. Ann Intern Med 136:280-287.

Versalovic J (2003) Helicobacter pylori. Pathology and diagnostic strategies. American J Clin Pathol 119:403-412.

Associate Editor: Luis Carlos de Souza Ferreira 